\title{
Research collaboration tools for the U.S. Department of Defense
}

\author{
Sandy I. Schwalb \\ Defense Technical Information Center, 8725 John J. Kingman Rd., Ft. Belvoir, VA 22630, USA \\ Tel.: +1 703767 9205; Fax: +1 703767 8032; E-mail: sschwalb@dtic.mil
}

\begin{abstract}
America's adversaries have shown their ability to quickly incorporate new technologies that threaten the U.S. and its interests. The Defense Technical Information Center (DTIC) serves the Department of Defense (DoD) research and engineering community as the central resource for DoD-funded scientific, technical, engineering, and business information and exchange. Furthermore, DTIC fulfills a key role by producing secure collaborative tools that facilitate a rapid response to current and emerging threats. The new Research \& Engineering (R\&E) Gateway (created by DTIC), which includes DoDTechipedia, DoDTechSpace, Search and Analytics, and the Information Analysis Centers and Defense Innovation Marketplace, are aimed at enhancing DoD's ability to collaborate across the defense enterprise, identify solutions for technology challenges, and seek ways to ensure that taxpayer dollars are spent in an efficient manner. This article will examine the approach taken to develop the collaborative tools, intended goals, challenges to adoption of the sites, and some lessons learned. It will also review how DTIC has provided its registered customers with robust social media tools, albeit limited to the defense community.

Keywords: Defense information, scientific and technical information, research, development, test and evaluation, social media, social business tools, wikis, secure collaborative tools, information security, information sharing, independent research and development, technological superiority
\end{abstract}

\section{Introduction to DTIC}

The Defense Technical Information Center (DTIC) is the largest central resource for defense and government-funded scientific, technical and engineering information available today, with more than four million records in its collection. DTIC is also responsible for the management of the Information Analysis Centers (IACs: see http://www.dtic.mil/dtic/iac/), a nearly $\$ 2$ billion enterprise supporting research and analysis. DTIC leads DoD website development, having designed, executed and hosted more than 70 DoD sites. A DoD Field Activity, DTIC reports directly to the Assistant Secretary of Defense (ASD), Research \& Engineering (R\&E).

\section{Reaching our customers}

DTIC offers products and services to the diverse population of the defense community. Due to the nature of the information it handles, individuals must register with DTIC in order to take advantage of value-added services. Registered users can have research performed by trained information professionals and can obtain access to information not publicly available (sometimes referred to as "limited information" or "controlled unclassified information"). Individuals eligible to register include employees of a DoD organization or the U.S. federal government, DoD or U.S. federal government contractors, researchers at a university or college funded by DoD or a U.S. federal government agency for con- 
ducting research throughout the U.S., participants in certain small business programs and faculty/staff members or students of specific minority colleges/universities. DTIC's registered customers can also be part of the intelligence community or certain foreign governments (e.g., negotiated agreements with Australia, Canada and the United Kingdom). More information about registering with DTIC can be found at http://www.dtic.mil/dtic/registration/.

\section{A key player in DoD}

America's adversaries have shown their ability to quickly incorporate new technologies that threaten the U.S. and its interests. DTIC, which has been part of DoD for close to 70 years, fulfills a key role by producing secure, collaborative tools that facilitate a rapid response to current and emerging threats.

In order to ensure that the money DoD has appropriated for scientific and technology activities, projects and programs is spent wisely, DoD has reviewed ways to foster better collaboration among its more than 70,000 researchers and engineers. Indeed, there are numerous technology challenges faced by DoD:

- Ensuring that existing scientific and technical investments are more accessible and available to stakeholders.

- Accelerating the pace for fielding new capabilities for the warfighter.

- Taking advantage of innovations occurring rapidly in industry.

- Ensuring that solutions are implemented across the military services and the entire DoD enterprise.

- Eliminating duplicative efforts.

- Acting as a good steward of taxpayer dollars.

- Seeing that DoD is an appealing employer by providing tools familiar to the next generation of scientists, engineers and researchers.

\section{Social media}

While DTIC continues to branch out into the external world of Facebook, LinkedIn, etc., it has been offering secure social media tools to its more than 28,000 registered users over the past five years. By building these innovative tools, DTIC has sought to accomplish the following:

- Maximize DoD's research and engineering investment.

- Transform collaboration from the lab bench to the battlefield.

- Synthesize data to provide decision makers with situational awareness.

- Simplify and expand the capture of research and engineering data.

- Preserve and share research and engineering knowledge: sustain artifacts as the foundation to future research.

- Help the defense community avoid reinventing/reengineering the wheel.

\section{DTIC's transition}

DTIC traces its origins back to World War II. In 1948, DoD formally created the Central Air Documents Office (CADO), a predecessor to DTIC, to hold the combined collections of captured German technical documents and U.S. research and development documents from the war years. For its close to 
70 years of existence, DTIC has made DoD-funded research available to scientists and engineers, first in paper and microform, then in online databases.

DTIC is now in the midst of a transition from a static repository of information focused on capture, preservation, and paper dissemination to a technology organization committed to accelerating the flow of information within DoD and working with its partners in industry and academia.

\section{Encouraging information sharing}

Due to funding mechanisms and traditional barriers between organizations, DoD culture has encouraged communities to keep their projects closely held. In a world that continues to be more networked, however, it is important that the defense workforce has the tools that will enable them to create, capture, share, and reuse the knowledge developed throughout DoD. DTIC has made great strides in creating and hosting sites aimed at enhancing the ability to collaborate across the defense enterprise and industry.

Launching social media products in an environment that prides itself on keeping information secure comes with challenges. Convincing users that sharing information within the community is beneficial can be difficult at times. Even when employees (within or outside the government) want to share, they are often hesitant or told by management to have all information approved prior to posting. Overcoming these cultural norms is challenging. Being able to clearly state the worth provided by the tool in an employee's daily work can be a key factor in its ultimate acceptance. Can the tools be shown to be of greater value than the risk perceived by members of the community? It is also critical to utilize the leadership to demonstrate and encourage use.

While technology is not simple, it can be a defining factor in building and implementing these tools. However, lowering cultural barriers to sharing can be more difficult. Younger scientists and engineers are less resistant to the use of web and social media tools, more conservative approaches do point to the fact that a balance is needed between sharing and access restrictions. Some scientists and engineers are leery about sharing because of the implications of the data involved. In other cases, resistance to disseminating information can be due to proprietary data, patentability issues, or even competition for funding.

The Research \& Engineering (R\&E) Gateway, DoDTechSpace, DoDTechipedia and the Defense Innovation Marketplace, go a long way toward helping to start the discussions about identifying solutions for technology challenges while also aiding in accelerating the pace for fielding new capabilities for the warfighter.

\section{Research \& Engineering (R\&E) Gateway: A connected DoD = challenges solved}

A new venture for DTIC, the R\&E Gateway (Fig. 1), is scheduled for launch by the end of fiscal year 2013 (September 2013). It is designed to provide seamless access to official defense scientific and technical information, collaborative tools and subject matter experts for DoD and industry partners. The gate-

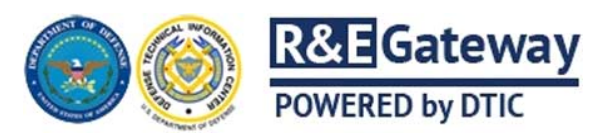

Fig. 1. The New Research \& Engineering (R\&E) Gateway: a connected $\mathrm{DoD}=$ challenges solved. (Colors are visible in the online version of the article; http://dx.doi.org/10.3233/ISU-130710.) 
way provides the ability for the DoD community to build on past work, collaborate on current challenges, avoid duplication of effort, aid decision makers, and support management of the DoD S\&T enterprise.

The R\&E Gateway is a collaborative and secure environment in which DoD and industry partners, even when separated by geography, time and organization structures, can access a range of information and data. The gateway can connect the defense research and engineering community, DoD laboratories, warfighters and other DoD agencies, in addition to providing current and next-generation researchers with advanced web 2.0 tools. Offering real-time discussions on capability needs and solutions, events and people, the R\&E Gateway is designed to support community activities, social networking, lessons learned and discussions.

Here are some of the tools that are available in the R\&E Gateway:

DoDTechipedia - one of DoD's first S\&T wikis, designed by DTIC, enables sharing and updating of technology development information, in real time, by the community. It offers a secure space to store and share research data (see more below).

DoDTechSpace - a new virtual collaboration environment where the community can engage in dialogue, create content, coordinate on projects and connect with colleagues. It is a planning tool to coordinate, discuss, consolidate and track project data.

Search - is available across DTIC platforms and shows top hits from DoD current or past research; intuitive options to refine one's search; and ability to discover people, places and content from the DoDTechSpace community.

Analytics tool - access S\&T funding information that includes congressional budget data and business information on DoD Labs. Data is displayed in charts and graphs, which users can manipulate and export.

\section{DoDTechipedia}

One of DoD's first scientific and technical wikis, DoDTechipedia (Fig. 2), was launched by DTIC in 2008. Using Confluence software, DTIC developed this tool to provide an encyclopedia-like resource

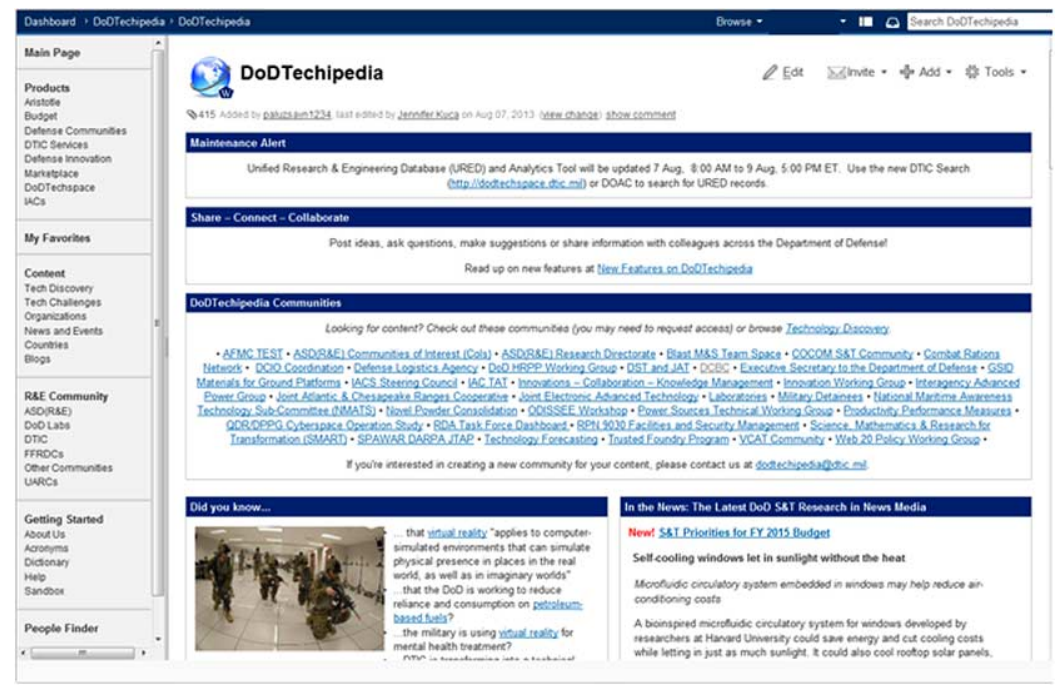

Fig. 2. DoDTechipedia, launched by DTIC in 2008, was one of DoD's first S\&T wikis. (Colors are visible in the online version of the article; http://dx.doi.org/10.3233/ISU-130710.) 
of science and technology information in a wiki environment. Open to all DoD and federal government employees and contractors, DoDTechipedia offers a collaborative environment ensuring greater transparency and communication among defense scientists, engineers, program managers, and warfighters. Discussions, articles and documents on the wiki can be opened to a broad community, so that those with questions/requirements can connect with those who have solutions.

After DoDTechipedia's launch, some segments of the defense community brought up issues about how much information should be shared. A key concern was whether information being shared would remain secure or if material posted by an individual should be "run up the chain", including reviews/screenings by supervisors and/or public affairs. It became clear that input from the community was instrumental to the success of DoDTechipedia. DTIC looked to Pentagon leaders, who had pushed for the creation of DoDTechipedia, to communicate to the DoD scientific and technical community how valuable the wiki was for sharing knowledge, assisting colleagues, posting events, starting blogs or being part of the knowledge network.

In fact, within a few weeks of DoDTechipedia's 2008 launch, then Under Secretary of Defense, Acquisitions, Technology and Logistics, John J. Young, Jr., sent a message to the defense laboratories directing all scientific and technical teams, "to populate DoDTechipedia with the details of current and planned technology investments", and that program managers were to "use this tool to identify solutions for technology challenges and opportunities to mature and transition those technologies".

Additionally, DTIC staff engaged in grassroots marketing of the wiki to defense communities, including the Combatant Commands (nine military organizations, each having a broad geographic or functional responsibility) and new technology adopters through briefings, newsletters, advertisements, articles, onsite training and webinars. Since DoDTechipedia's launch, more than 22,000 pages of content have been added, and 4,000 communities have contributed articles covering DoD's scientific and technical priorities, research and engineering topics, and active links to search-related technical reports in DTIC's large collection.

In 2009, DoDTechipedia was awarded the Government Computer News 22nd annual award for Outstanding Information Technology Achievement in Government. The wiki was also highlighted on the White House website in the Open Government Initiative/Innovations Gallery.

In the summer of 2013, DoDTechipedia unveiled a new look and a user interface that makes adding and editing content as easy as using a word processor.

\section{Success story: Defense Communities}

A section within DoDTechipedia includes "Defense Communities", which is a secure, non-public site for DoD-only collaboration. As of this writing, it is comprised of more than 60 wiki communities.

A major success story for DTIC was the development of the Acquisition Information Repository (AIR) on Major Defense Acquisition Programs. This site was to provide the defense acquisition community with timely, secure access to the milestone information required for oversight of the programs. The project's customers decided to host the AIR within DoDTechipedia and noted that it "has proven to be an extremely beneficial and cost effective solution to the department's need for the centralized storage of acquisition information". The customers stated that the work of the DTIC project team should "be commended for their efforts and talents that took this system from concept to initial operational capability in only six months". In fact, the Under Secretary of Defense, Mr. Frank Kendall, in a memo to the Pentagon leadership, called for the use of this wiki space as a repository for acquisition information. 


\section{Defense Innovation Marketplace}

The Defense Innovation Marketplace, or "the Marketplace" (Fig. 3), was launched in 2011 as an online resource (both public and limited) for DoD and industry to use to exchange information. This site was created as a direct result of the "Better Buying Power" initiative put forth in 2010 by then Under Secretary of Defense for Acquisition, Technology and Logistics, Mr. Ashton Carter. The initiative called for DoD to deliver better value to the taxpayer and warfighter by improving the way it was doing business. In this mandate, the Independent Research and Development (IR\&D) program was highlighted as a program in need of reinvigoration.

For nearly 80 years, private companies doing business with $\mathrm{DoD}$ were able to recover some of their research and development costs as part of the general and administrative expenses charged to existing contracts. Firms had the independence to decide which technologies to pursue with these funds as long as these efforts were of potential interest to DoD.

Private firms were initially required to report their IR\&D results to DTIC, but in the mid-1990s, this became a voluntary program. Not surprisingly, this led to a decrease in the amount of reporting. For instance, in the year 2000, more than 10,000 IR\&D reports were submitted to DTIC; by 2011, that number had fallen to 1,000 . It was clear to DoD leaders that DoD was losing an important link between funding and technological purpose, and there was a need to ensure that a secure, user-friendly avenue be available for industry and DoD to collaborate.

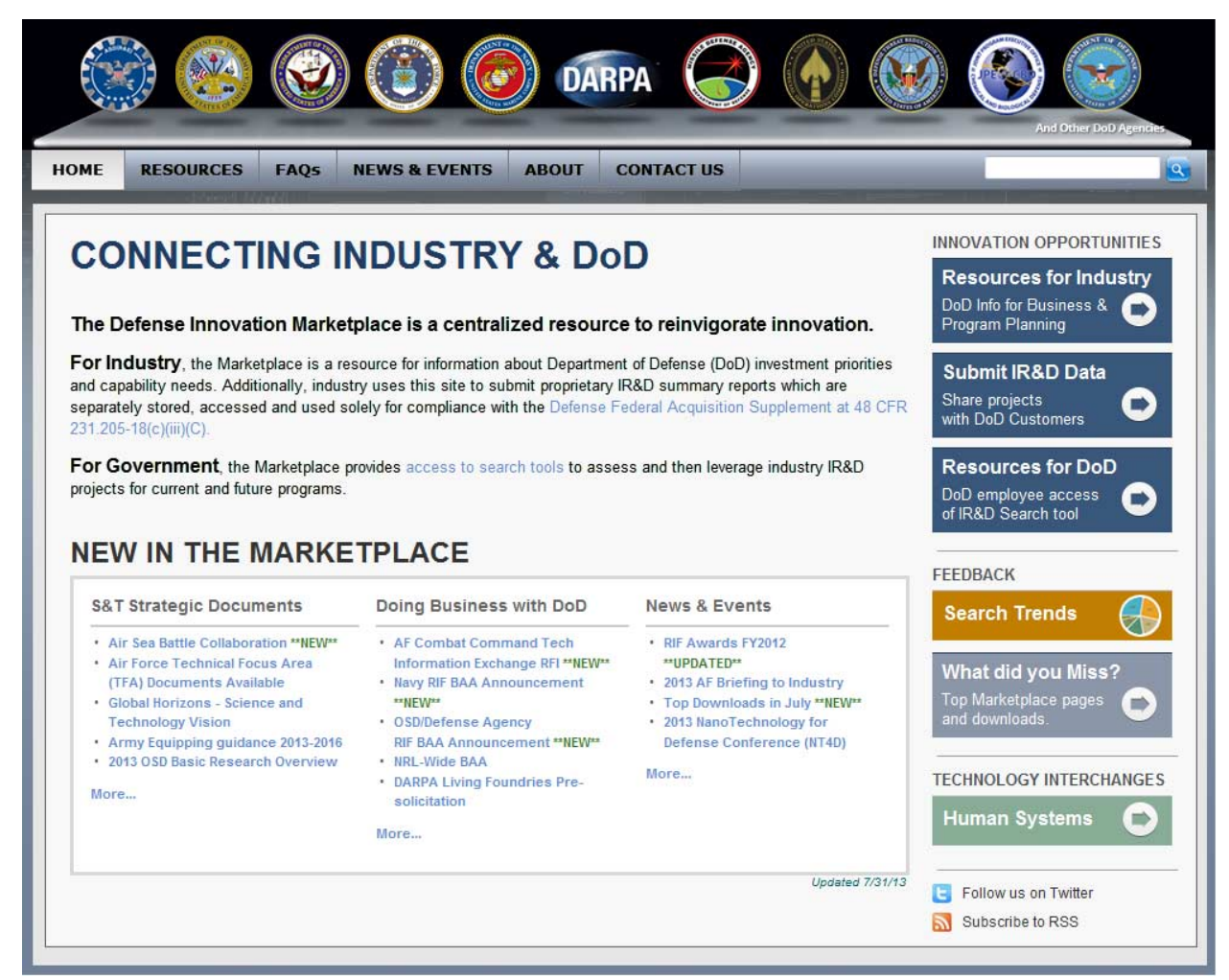

Fig. 3. The Defense Innovation Marketplace: connecting industry and government customers. (Colors are visible in the online version of the article; http://dx.doi.org/10.3233/ISU-130710.) 
In January 2012, major DoD contractors who receive more than $\$ 11 \mathrm{M}$ for IR\&D funding were required to provide details of their efforts in the Marketplace. The site is expected to show to DoD its return on investment of the more than $\$ 4 \mathrm{~B}$ of IR\&D funds it spends each year. This will allow DoD to more easily use the knowledge of how industry is planning out future acquisitions and to highlight gaps in research areas.

Security needs have made development of this site more complex. A major challenge for the Marketplace was to ensure that access to the proprietary data was restricted to government users only. In fact, much of the data provided by industry is highly proprietary and cannot be seen by contractors; nor can it be seen by a majority of DoD personnel. The Marketplace project team continues to examine innovative solutions as DoD transitions to the universal use of exclusive Common Access Card admission to systems (http://www.defenseinnovationmarketplace.mil/).

For DoD acquisitions personnel, a search capability has been created for the IR\&D data, showing projects, companies and dollars. In FY14 (starts October 2013) records of expenditures by DoD laboratories, small businesses and industry will also be included, so that an acquisitions planner can see at a glance what technologies industry is developing and what DoD sources are developing, and their level of development.

\section{Planning for new technologies}

Until recently, information sharing between DoD and industry entailed (1) DoD holding a workshop to brief interested industry representatives on DoD goals and needs in certain technical areas, (2) industry considering the information that DoD provided, and (3) industry proposing technologies to DoD that might solve needs highlighted during the briefing.

Using the Marketplace, DoD can now request that industry enter technologies from IR\&D or other efforts to solve DoD needs. DoD technical experts can use the Marketplace tools to analyze the state of technology and to ask selected industry partners to elaborate on them, allowing $\mathrm{DoD}$ to review which technologies have the potential for application considerations in its investment strategy. This online process can foster collaboration with all interested parties, regardless of location, saving time and money.

The Human Systems and Space Communities of Interest were the first subject area groups to use the capabilities of the Marketplace and hold this type of meeting. Using technology to reduce costs to the taxpayer while still performing the essential DoD technology missions meets the national security goal of technological superiority.

\section{Conclusion}

During DTIC's development of collaborative tools for the defense enterprise, many challenges have been met and numerous lessons have been learned.

It became increasingly clear to those who designed and implemented these tools that DTIC's customers needed a "gateway" that showed the connections between the products being offered and their usefulness in everyday business processes. The R\&E Gateway project team looked at how the products worked together, as in: a more robust search tool, editable wiki, a space for secure online discussions and problem-solving, all while having access to DTIC's vast collection of information and data.

The R\&E Gateway, while a DoD-wide tool, also provides a secure space for small groups to work together, to discuss and to solve problems. 
To ensure buy-in from scientists, engineers, project officers and program managers who use DTIC's tools, it is critical for leadership, ranging from teams within an organization to those in charge at the Pentagon, to show their support for those products, programs and/or projects. But if that support is seen as a "do as I say, not as I do", approach, the buy-in won't come. What can work is staff seeing their leaders actually using the tools; writing a blog; starting or participating in an online discussion, etc.

DTIC has been in the information business for close to 70 years and remains the central location for DoD research and engineering/scientific \& technical information by preserving knowledge, connecting people, and inspiring innovation. Despite severe budget pressures facing the whole of $\mathrm{DoD}$, the requirement for S\&T communities to work together and collaborate remains a high priority. DTIC continues to be a leader in designing, building and supporting a robust set of complementary collaborative tools for DoD's S\&T workforce. 